відбракування піків зображення, в околииі яких відсутні сигнали від небесних об'єктів, виробляється наближене виділення нормальної («фонової») складової суміші розподілів значень просторової згортки по розробленому обчислювальному методу. Метод використаний авторами в розробленій системі автоматизованого виявлення нових $i$ відомих астероїдів.

Ключові слова: сигнали -методи виявлення, серія ПЗ3-кадрів.

\title{
Preselection of celestial objects' signals on CCD-image
}

\section{E. Savanevich, A. B. Bryukhovetskiy, A. M. Kozhukhov, A. S. Syrovatka}

The method of preselection of celestial objects' signals, which is based on comparing values of spatial convolution of the accepted radiation, close to image's peak, and by a mask, corresponding to the form of the expected signal to the threshold is offered. The new model of distribution of spatial convolution values, which is represented by a mixture of normal distribution law and "tail", which is situated in the area of large values of spatial convolution is offered. An approximate selection of normal ("base-line") component of distribution of spatial convolution values is followed by the developed computational method for determination of rejection threshold of image's peaks, close to which celestial objects' signals are absent The method is used by authors in developed system of automatic online new and known asteroids tracking.

Keywords: signals - methods of detection, CCD-frames series.

УДК 623.451.4.082.5; 623.56

\author{
А.Б. Тимошенко ${ }^{1}$ И.Б. Чепков ${ }^{2}$ \\ ${ }^{1}$ Министерство обороньл Украины, Киев \\ ${ }^{2}$ Центральный научно-исследовательский институт вооружения и военной техники \\ Вооруженных Сил Украины, Киев
}

\section{МОДЕЛИРОВАНИЕ ФУНКЦИОНИРОВАНИЯ БОЕВЫХ ЧАСТЕЙ, СОДЕРЖАЩИХ СНАРЯДОФОРМИРУЮЩИЕСЯ ЭЛЕМЕНТЫ}

В работе представлены результаты численного моделирования процесса функционирования кумулятивных струй, образующихся в результате подрыва зарядов ВВ, содержащих полусферические (сегментные) облицовки. Получена информация об изменении во времени и в пространстве параметров движения и состояния поражающего элемента. В работе предпринята попытка, экспериментально определить условия функиионирования боеприпасов, использующих снарядоформирующиеся элементь.

Ключевье слова: моделирование, боеприпасы, использующие снарядоформирующиеся элементы.

\section{Постановка проблемы. Анализ последних исследований и публикаций}

Наиболее важным моментом в процессе функционирования боеприпасов содержащих снарядоформирующиеся элементы (СФЭ) является период формирования и взаимодействия поражающего элемента с броней.

Механізм формирования снарядоформирующегося элемента из металлической тонкостенной облицовки состоит из отбора химической энергии ВВ и трансформации значительной её доли в кинетическую энергию поражающего элемента. В отличие от классической кумулятивной струи, образование которой происходит при сверхвысоких давлениях в зоне соударения (симметричных относительно продольной оси заряда) элементов кумулятивной облицовки, ударное ядро формируется за счёт выворачивания кумулятивной облицовки как целого с последующим относительно “мягким” обжатием в радиальном направлении и получением компактного снаряда. Если в классическую кумулятивную струю переходит $10 . .20 \%$ массы кумулятивной облицовки, то в ударное ядро - практически вся её масса $[1,2]$.

Анализ конструктивного исполнения СФЭ показывает, что оптимальные конструкции конических кумулятивных облицовок имеют высоту, сравнимую с диаметром основания конуса, а конические или сферические кумулятивные облицовки, из которых образуются ударные ядра, имеют отношение высоты к диаметру основания в пределах $0,1 \ldots 0,3$. Максимальная скорость стального или медного ударного ядра для современных конструкций СФЭ составляет $2200 \ldots 3500 \mathrm{M} / \mathrm{c}$.

В работе [3] проведен анализ методов математического моделирования функционирования снарядоформирующихся элементов и результаты теоретических исследований. Исследование процесса 
функционирования кумулятивных зарядов с полусферическими и сегментными облицовками средствами численного моделирования проведено в работах $[4,5]$. Данные работы посвящены главным образом теоретическому изучению механизма формирования кумулятивных струй на основе классической гидродинамической теории применительно к компактным поражающим элементам при малом отношении длины к диаметру $L / D$. Однако содержащиеся в них рекомендации и выводы по конструированию таких кумулятивных зарядов основаны на экспериментальных данных, что ограничивает всестороннее исследование особенностей функционирования СФЭ, таких как распространение детонационных волн, по заряду ВВ, формирование струи (разгон облицовки) и ее взаимодействие с преградой.

Изучение механизма формирования кумулятивных струй экспериментальными методами затруднено из-за малой длительности процесса, невозможности наблюдения волновых процессов в ВВ, процесса деформирования облицовки, а также самой кумулятивной струи во время ее растяжения и разрыва. В этой ситуации целесообразно заменить физический эксперимент численным, т.е. основные параметры кумулятивных зарядов определить путем математического моделирования процесса формирования кумулятивных струй. Подобные расчетные методики дают возможность получать априорную экспертную оценку того или иного технического решения с точки зрения его работоспособности и эффективности, исследовать влияние параметров конструкции и физикомеханических характеристик материалов ее элементов (в том числе и ВВ) на функционирование конструкции в целом, определять закономерности того или иного процесса, лежащего в основе конкретного инженерного решения.

\section{Цель статьи}

Цель данной работы заключается в численном моделировании процесса функционирования кумулятивных струй, образующихся в результате подрыва зарядов ВВ, содержащих полусферические (сегментные) облицовки, позволяющие получить информацию об изменении во времени и в пространстве параметров движения и состояния СФЭ. Выработка практических рекомендаций по определению оптимальных условий формирования кумулятивных струй выходит за рамки данной работы и будет выполнена позже.

\section{Изложение основного материала}

Методика исследования. Изучение процессов схлопывания облицовки и формирования кумулятивной струи СФЭ можно проводить как в двухмерной (плоская задача деформирования, осесимметричная задача), так и в трехмерной постановке (с учетом симметрии конструкции относительно координатных плоскостей или полная трехмерная модель). Отметим, что сквозной расчет функционирования кумулятивного заряда на основе численных методов механики сплошных сред от момента инициирования до окончания пробития преграды сопряжен с определенными трудностями, вызванными, прежде всего, несовершенством физико-математических моделей разрушения кумулятивной струи и значительной трудоемкостью вычислительного процесса. Поэтому, по аналогии с физическим экспериментом, определим основные этапы исследования.

1. На основе анализа объекта моделирования и исследуемого процесса формулируются соответствующие геометрическая и физико-математическая модели, включающие в себя разрешающие системы дифференциальных уравнений, начальные и граничные условия, а также физические характеристики материалов конструкции боевой части.

2. С помощью программного обеспечения проводятся численные расчеты, обеспечивающие возможность варьирования значений физикомеханических характеристик изучаемых сред и параметров их взаимодействия в широком диапазоне, а также исследования их взаимного влияния на характеристики изучаемого явления или процесса.

3. Анализ и обобщение полученных результатов и внесение коррективов в алгоритм расчета. Такая обратная связь позволяет совершенствовать методологию проведения вычислительного эксперимента.

Критерием, определяющим достоверность результатов, полученных численными расчетами, и адекватность сформулированной физико-математической модели реальному процессу, является соответствие расчетных и экспериментальных данных.

Объект исследования. В качестве объекта исследования выбрана боевая часть, формирующая кумулятивную струю в виде снарядоформирующихся элементов.

В настоящей работе исследованы процессы формирования кумулятивных струй для двух способов инициирования:

- инициирование одним детонатором в центре задней части заряда ВВ (центральное инициирование);

- инициирование по окружности в задней части цилиндрического корпуса заряда ВВ (эксцентрическое инициирование).

При построении математической модели СФЭ приняты следующие допущения:

- корпус боеприпаса принимался как абсолютно жесткая, так и деформируемая конструкция;

- расчетная модель представляет собой совокупность двухмерных конечных элементов и приведена на рис. 1;

- задача решалась в осесимметричной постановке. 
Рассматривались два варианта инициирования заряда ВB.

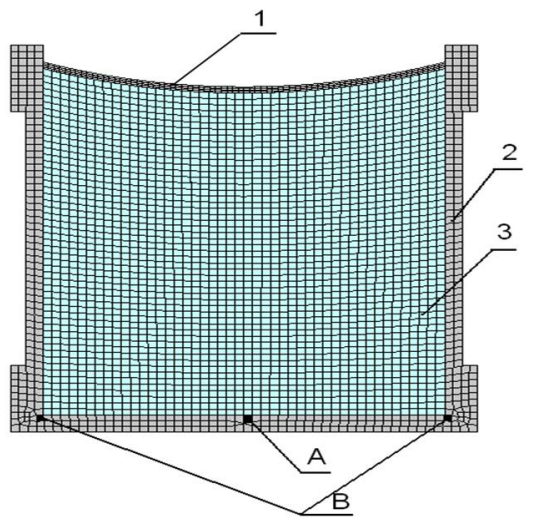

Рис. 1. Конечно-элементная модель задачи формирования кумулятивной струи:

1 - кумулятивная облицовка; 2 - корпус; 3 - взрывчатое вещество;

$A$ - точка инициирования в центре задней части заряда ВВ; $B$ - инициирование по окружности в задней части цилиндрического корпуса заряда ВВ

Результаты численного моделирования. Анализ формирования кумулятивных струй, полученных в результате численного моделирования, производили с помощью рекомендаций и программного обеспечения $[6,7]$, предназначенного для моделирования процессов высокоскоростного взаимодействия твердых тел произвольной конфигурации.

В качестве уравнений состояния материала облицовки использовалась модель Джонсона - Кука [8]. Материал облицовки - медь.
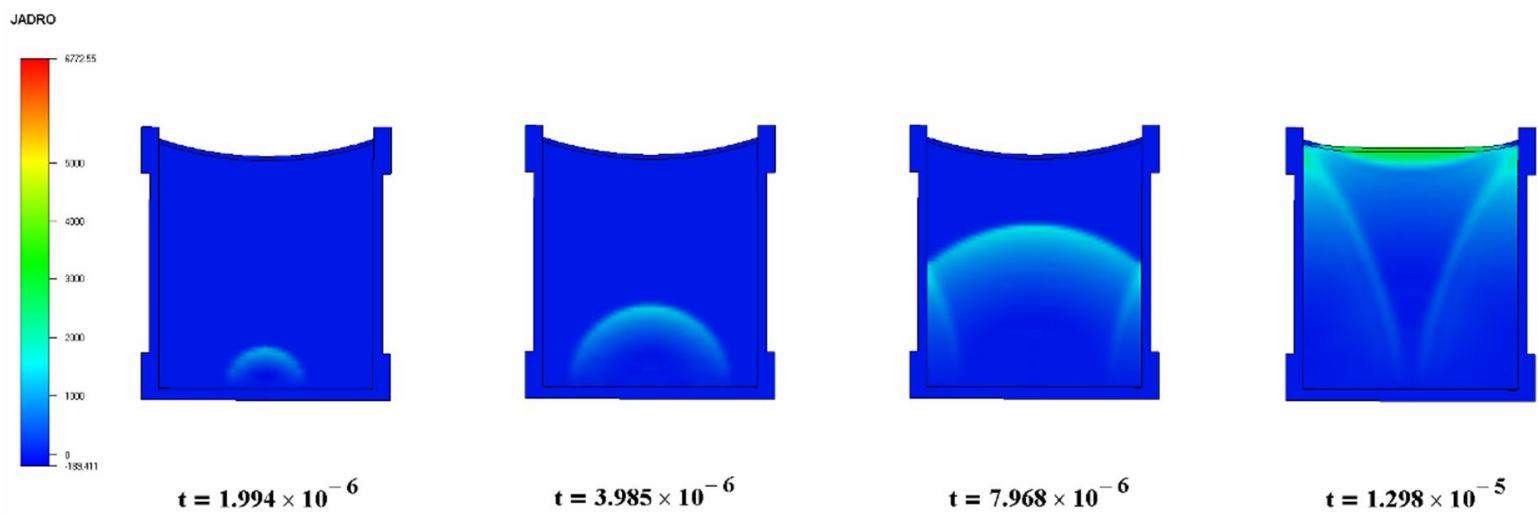

$t=3.985 \times 10^{-6}$
В качестве уравнения состояния взрывчатого вещества использовалась модель ДжонсаУилкинса-Ли ( JWL ) [9].

Результаты численного моделирования кумулятивной струи центральном инициировании заряда $\mathrm{BB}$ (точка $A$ ) и для эксцентрического инициирования (точка $B$ ) представлены на рис. 2, 3 .

На рис. 4, 5 приведены характерные стадии формирования кумулятивной струи на которых иллюстрируется эволюция облицовки СФЭ.

Заметно, что на первом этапе происходит выворачивание облицовки наружу с образованием целостного элемента, который имеет затупленную вершину и полость в основании. Здесь деформирование среды осуществляется с меньшими градиентами, чем при конусообразных облицовках с тем же начальным прогибом.

Представленные на рис. 4, 5 положения облицовки позволяют наблюдать эффект "выдавливания" центральной части. Результаты расчетов показывают, что наибольшее удлинение СФЭ равно 3...3,5. Это обусловливается разницей в развитии детонационных процессов (рис. 2, 3), которые характеризуются наличием вблизи оси симметрии значительной энергии сходящихся детонационных волн и, соответственно, повышением давления в продуктах детонации. Большее выдавливание происходит при эксцентричном инициировании. Таким образом, перемещением точки инициирования достигается формирование компактного или удлиненного поражающего элемента.

Рис. 2 Волновые процессы, происходяшие при централи JADRO

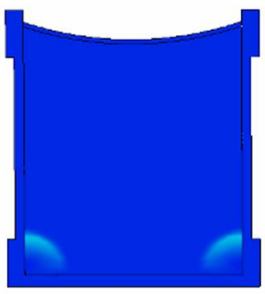

$t=1.994 \times 10^{-6}$

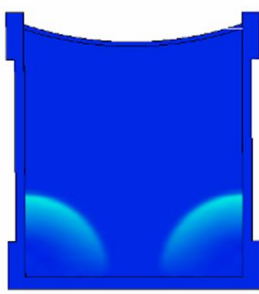

$t=3.985 \times 10^{-6}$

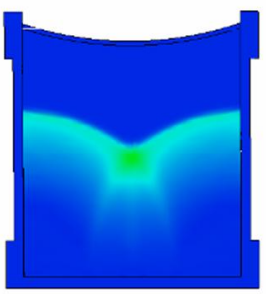

$t=7.968 \times 10^{-6}$

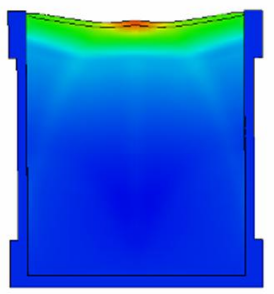

$\mathrm{t}=1.397 \times 10^{-5}$

Рис. 3. Волновые процессы, происходящие при эксцентрическом инициировании заряда ВВ в точке $B$

(C) А.Б. Тимошенко, И.Б. Чепков 

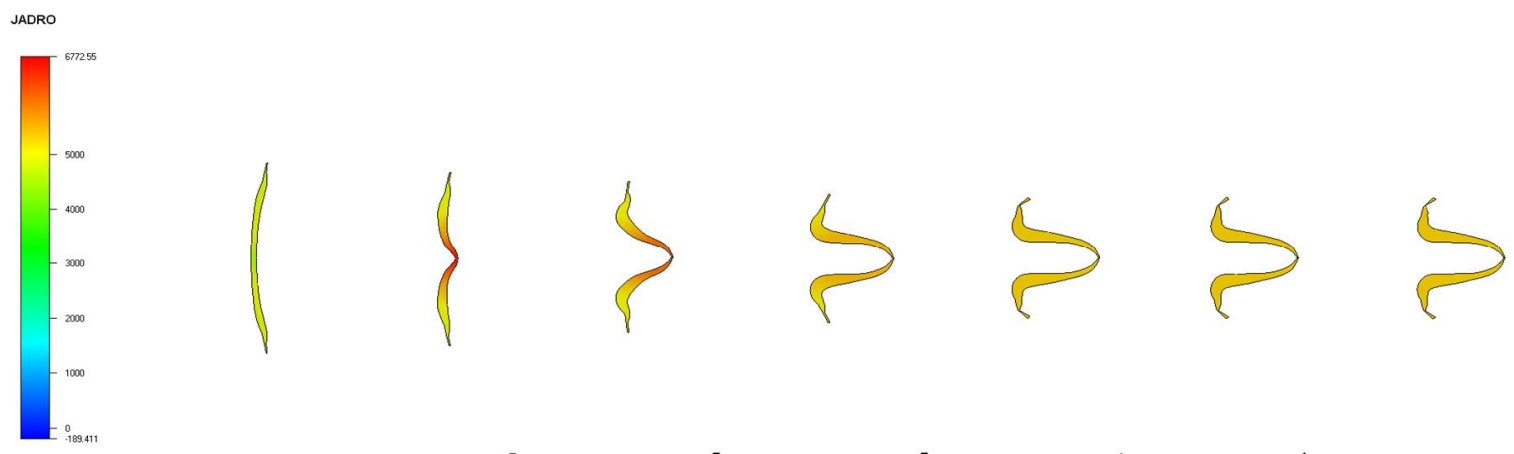

$t=2.298 \times 10^{-5} \quad t=3 \times 10^{-5} \quad t=4.3 \times 10^{-5} \quad t=6.399 \times 10^{-5} \quad t=1.47 \times 10^{-4} \quad t=2 \times 10^{-4} \quad t=2.17 \times 10^{-4}$

Рис. 4. Качественная картина формирования кумулятивной струи из сферической облицовки при центральном инициировании
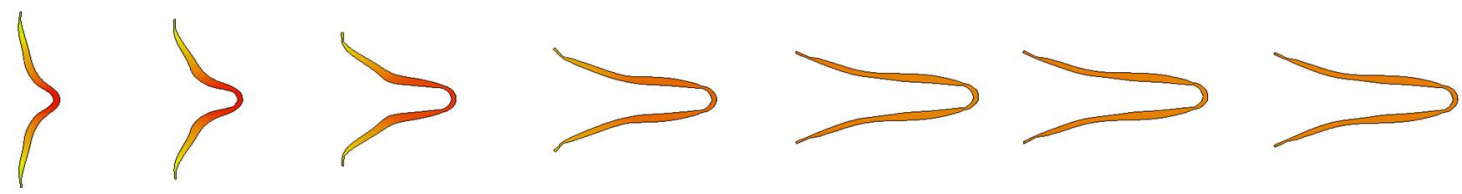

$\mathbf{t}=2.299 \times 10^{-5} \mathrm{t}=3 \times 10^{-5} \mathrm{t}=4.3 \times 10^{-5}$

$\mathbf{t}=6.398 \times 10^{-5}$

$\mathbf{t}=\mathbf{1 . 4 1} \times 10^{-4}$

$\mathbf{t}=1.75 \times 10^{-4}$

$\mathbf{t}=1.93 \times 10^{-4}$

Рuc. 5. Качественная картина формирования кумулятивной струи из сферической облицовки при эксцентрическом инициировании

Изменение относительной скорости $V / V_{\max }$ облицовки в зависимости от времени для центрального и эксцентрического инициирования изображено на рис. 6, 7.

Несмотря на имеющееся отличие в начале движения в осевой компоненте скорости, в процессе последующего деформирования происходит постепенное выравнивание скорости. В общем случае массовая скорость убывает по длине СФЭ от его головной части к хвостовой. Относительная монотонность функции течения процесса при компактировании облицовки приводит к формированию целостного СФЭ. Сравнение максимальных значений установившихся скоростей облицовок (рис. 8) свидетельствует о зависимости значений скорости СФЭ от места инициирования заряда ВВ.

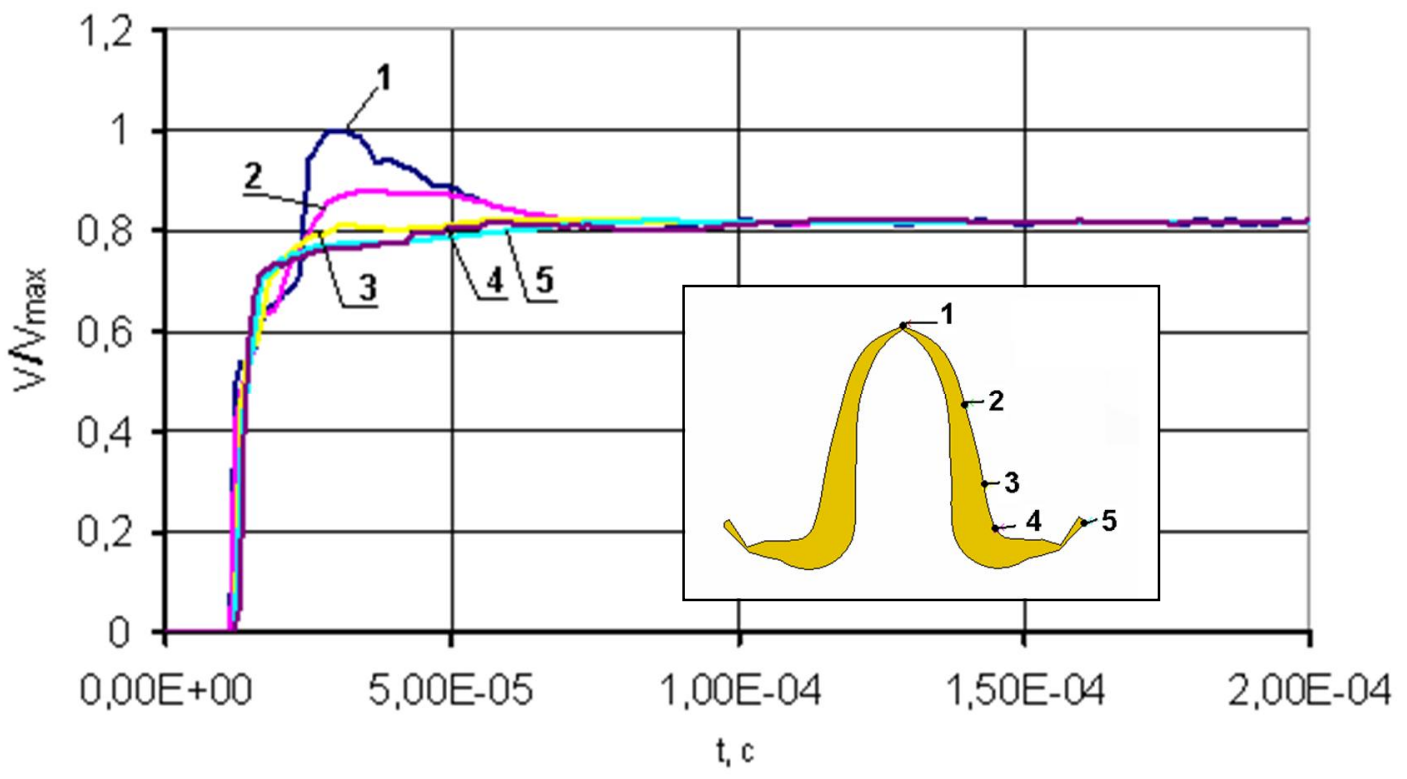

Рис. 6. Относительная скорость движения характерных точек $(1,2,3,4,5)$ облицовки при формировании кумулятивной струи (центральное инициирование)

(C) А.Б. Тимошенко, И.Б. Чепков 


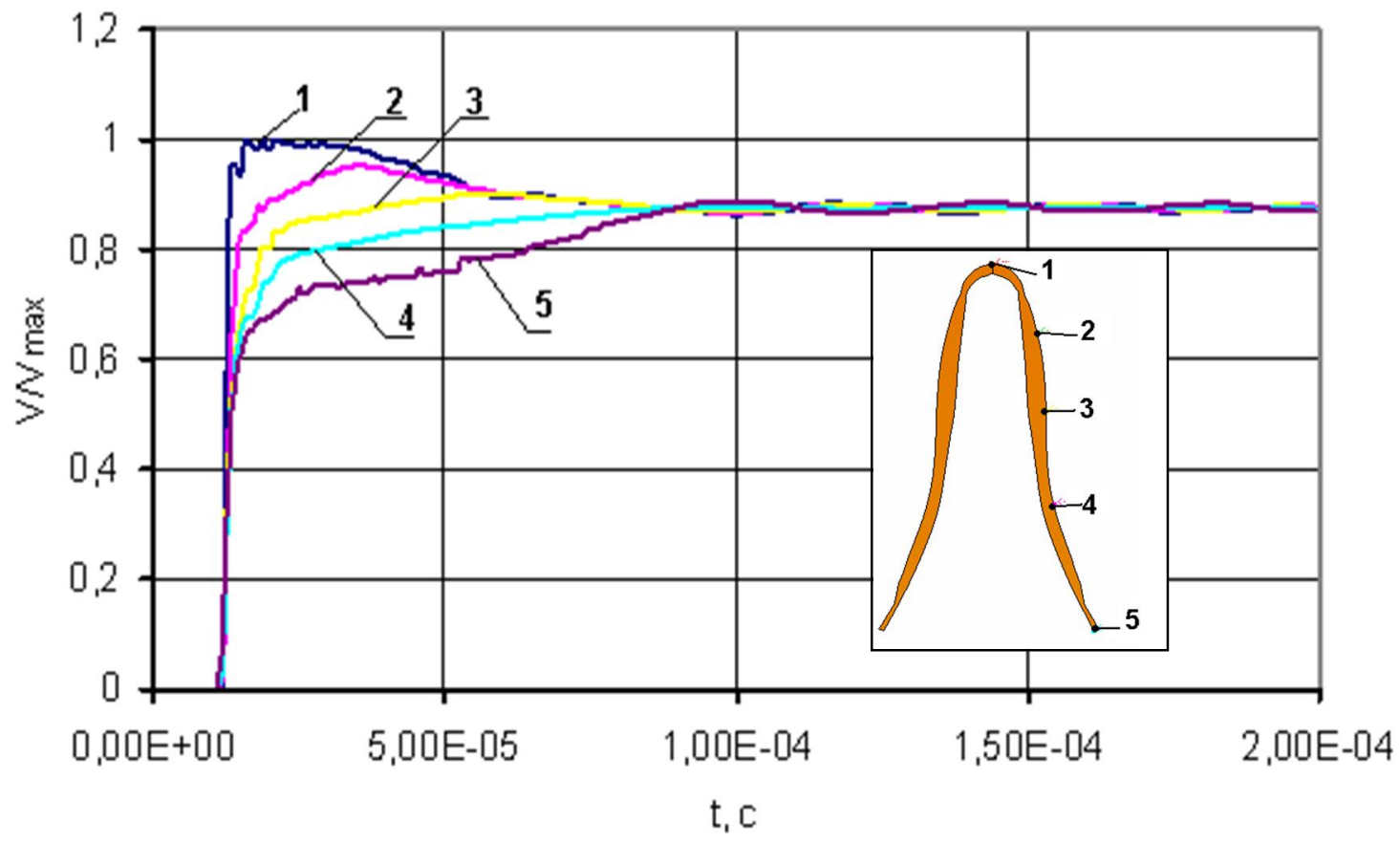

Рис. 7. Относительная скорость движения характерных точек $(1,2,3,4,5)$ облицовки при формировании кумулятивной струи (эксцентричное инициирование)

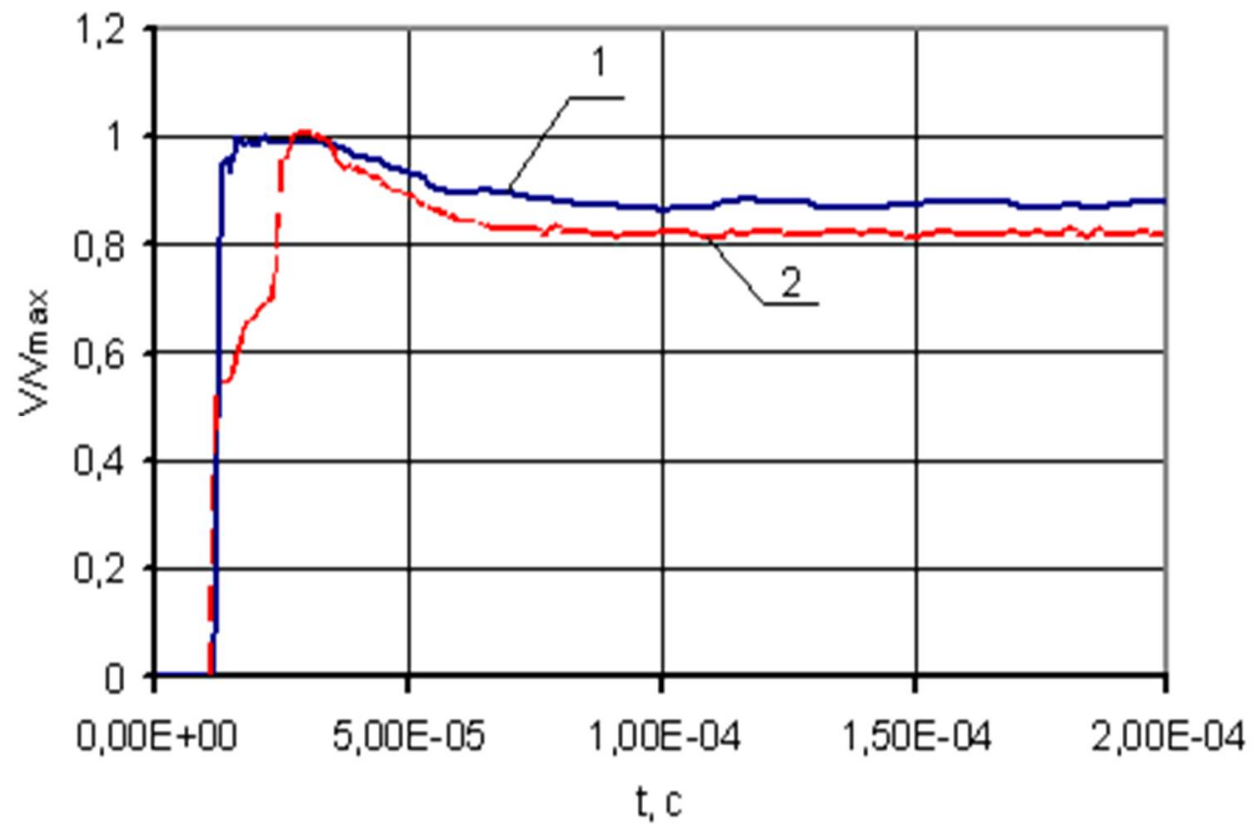

Рис. 8. Сравнения максимальных скоростей облицовок в зависимости от места инициирования: 1 - эксцентрическое инициирование; 2 - центральное инициирование

Для подтверждения изложенных результатов провели экспериментальные исследования, что позволяет оценить предложенную методику численного моделирования при проектировании кумулятивных зарядов боеприпасов повышенной точности.

Результаты экспериментальных исследований. Методика испытаний. В основу экспериментальных исследований была положена методика по определению бронепробивной способности сформированного поражающего элемента. Для достижения цели исследований решалась задача определения фактической бронепробиваемости СФЭ.

Испытания проводятся методом подрыва боевой части, образующей СФЭ в стационарном положении на заданном расстоянии от преграды (рис. 9).

При исследовании использовались три типа СФЭ, внешний вид которых показан на рис. 10. Вариант первый предназначался для поражения легкобронированной техники, а также для использования в тандемных боеприпасах. Макеты 
второго и третьего вариантов разрабатывались для поражения брони сверху. Испытываемые модели БЧ соответствовали по форме и характеру формирования ПЭ натурным образцам. Конструкция макетов БЧ в общем случае состоит из корпуса цилиндрической формы, выполненного из алюминиевого сплава (в первом варианте) и высокопрочной стали (во втором). Облицовка при помощи прижимного кольца крепилась к корпусу. Материалом для кумулятивной облицовок служила медь. В качестве взрывчатого вещества для снаряжения использовался сплав ТГ 50/50 и ТГ 63/37. Снаряжение осуществлялось методом кусковой заливки. В качестве дополнительного детонатора устанавливался линейный удлиненный заряд, снаряженный гексогеном.

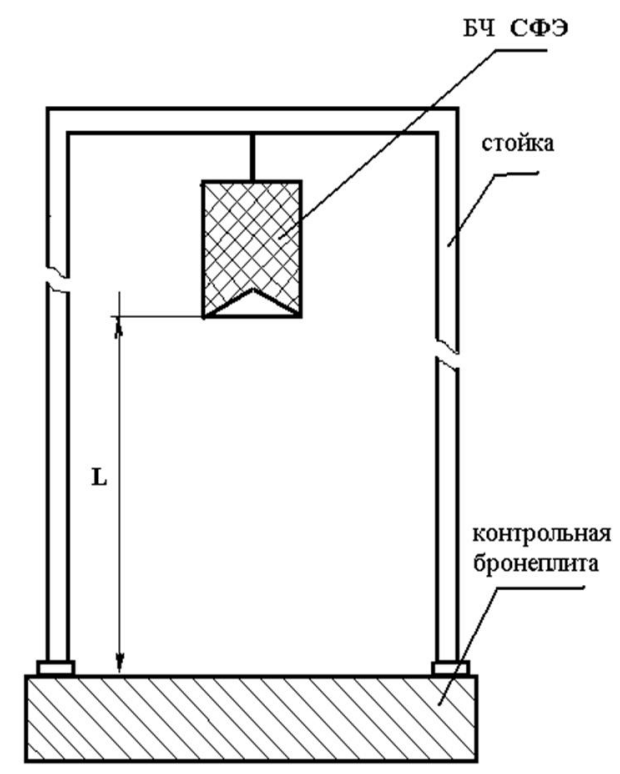

Рис. 9. Схема проведения испытаний

Результаты испытаний. Для определения фактической бронепробиваемости СФЭ была подготовлена мишенная обстановка (рис. 9), представляющая собой броневые плиты толщиной от 50 до 140 мм.

Заряды устанавливались в двух положениях: угол между осью заряда и перпендикуляром, проведенным к плоскости плиты, составлял $30^{\circ}$; ось заряда перпендикулярна к плоскости плиты (для вариантов 2 и 3 ).

При обработке мишенной обстановки после подрыва фиксировались следующие параметры: диаметры входного и выходного отверстия в случае пробития брони и глубина и диаметр кратера, глубина и диаметр откольного слоя в случае непробития.

Результаты испытаний приведены в табл. 1.

Наблюдавшиеся качественные закономерности процесса пробития, как показало сравнение опытных данных (табл.1), присущи в основном всем испытанным БЧ.

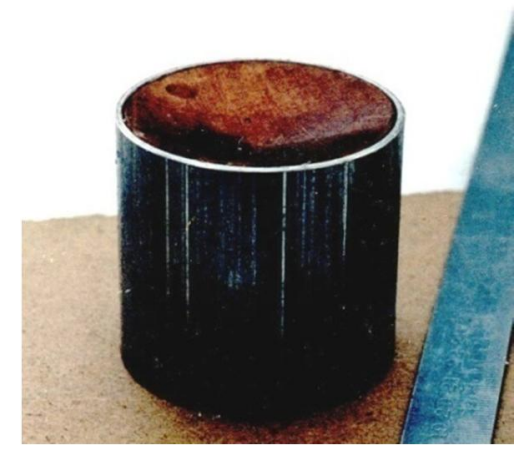

a

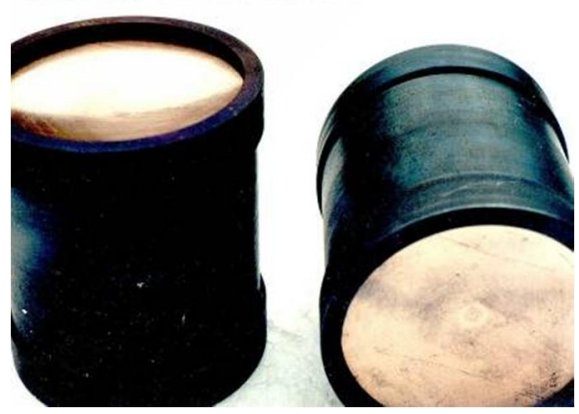

6

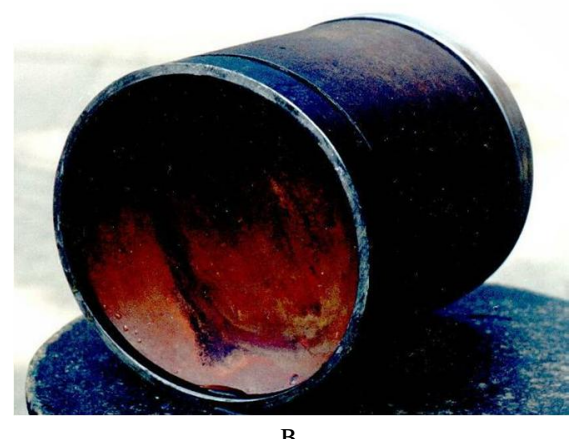

Puc. 10. Внешний вид БЧ с СФЭ:

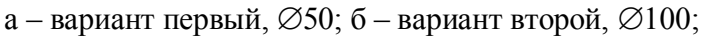
в - вариант третий, $\varnothing 158$

\section{Анализ результатов}

Полученный экспериментальный материал дает возможность проанализировать движение СФЭ в преграде по качественной и количественной информации.

О полученной форме СФЭ можно судить по характеру пробоины в броневой преграде (рис. 12).

Характер поражения свидетельствует об отсутствии разрушения облицовок в выбранном диапазоне прогибов. Причиной, позволяющей избежать разрушения СФЭ, является, по всей видимости, возникновение в материале облицовки в конце этапа разгона определенных радиальных компонент скоростей, направленных к оси и компенсирующих растягивающие усилия, возникающие в СФЭ при метании. Повидимому, если величина радиальных компонент скоростей превышает некую характерную для данного типа облицовки величину, то натекание материала на ось СФЭ становится слишком интенсивным, вследствие чего материал облицовки, растекаясь вдоль оси, уже не удерживается прочностными силами и разрушается подобно разрушению в кумулятивных струях. 
Результаты испытаний БЧ СФЭ

\begin{tabular}{|c|c|c|c|}
\hline Диаметр заряда, мм & Форма СФЭ & Толщина стальной брони, мм & Глубина пробития, мм \\
\hline 50 & компактный & 50 & сквозное \\
\hline 50 & удлиненный & 50 & сквозное \\
\hline 100 & компактный & 100 & 85 (рис. 11) \\
\hline 100 & удлиненный & 100 & сквозное \\
\hline 158 & компактный & 140 & сквозное \\
\hline 158 & компактный & 140 & сквозное \\
\hline 158 & удлиненный & 140 & сквозное \\
\hline
\end{tabular}

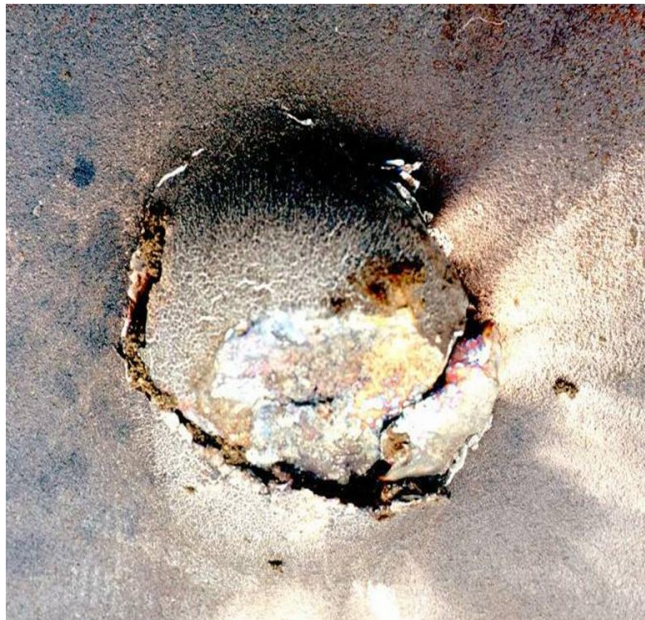

Рис. 11. Внешний вид откола на тыльной поверхности броневой плиты, образованного от СФЭ, Ø100

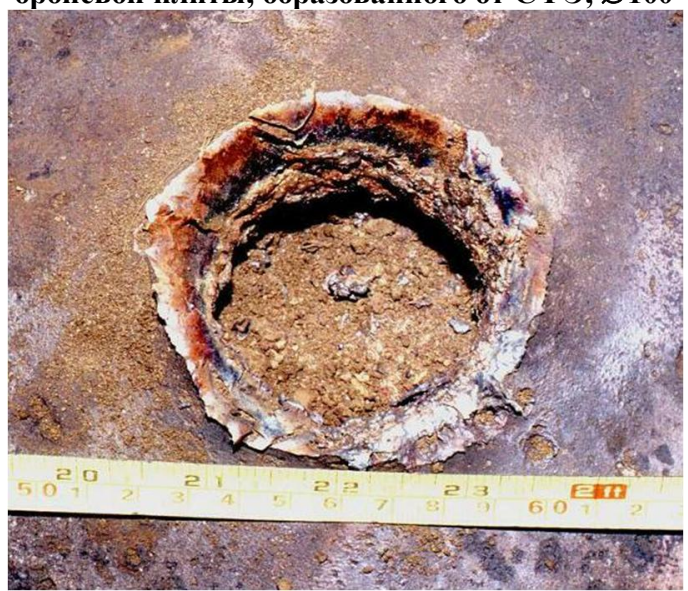

Puc. 12 a. Внешний вид кратера, образованного СФЭ, $\varnothing 158$. Лицевая сторона поверхности броневой плиты

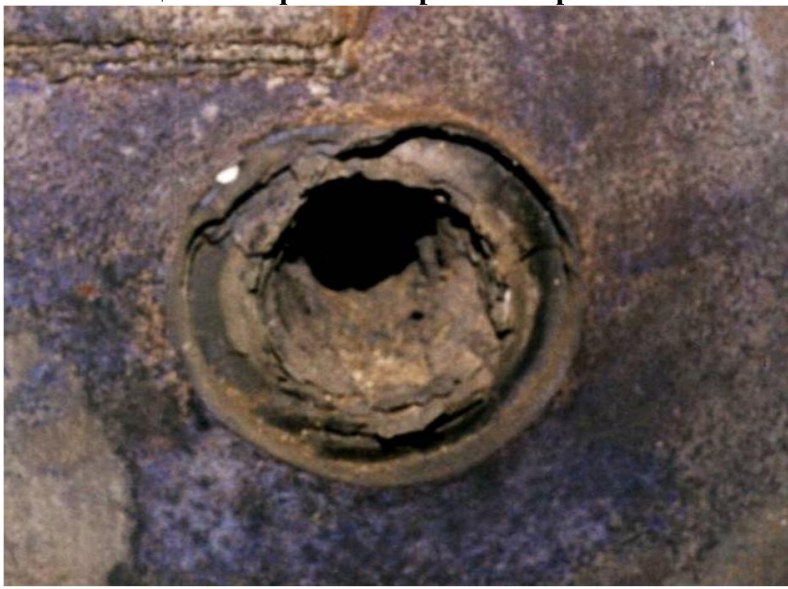

Рис. 12 б. Внешний вид кратера, образованного СФЭ, $\varnothing 158$. Тыльная поверхность броневой плиты
Проведенные исследования показали, что облицовки, используемые в данных опытах, формируют СФЭ, который сохраняет свою целостность.

Симметричность полученной формы достигнута технологическими приемами снаряжения БЧ, а также конструкцией крепления облицовки к корпусу, высокой точностью изготовления и одновременностью отрыва от элемента периферийных слоев облицовки. Наблюдавшиеся качественные закономерности процесса формирования СФЭ и пробития броневой преграды, как показало сравнение опытных данных, присущи в основном всем испытанным БЧ.

Между испытанными боевыми частями существуют принципиальные различия. При проектировании дальнобойных СФЭ необходимо выполнять требование неразрушаемости поражающего элемента в процессе взрывного метания, тогда как СФЭ, действующие на небольших расстояниях, могут формировать поток металла, обладающий сплошностью лишь в зоне действия по преграде.

Таким образом, метод взрывного формирования, реализуемый в СФЭ, дает возможность управлять характером действия поражающего элемента по цели, например, выбирать размеры отверстия, пробиваемого в преграде, регулировать уровень заброневого (запреградного) действия, выбирать дальность действия за счет изменений в конструкции СФЭ, приводящих к соответствующему изменению скорости, формы поверхности и внутренней структуры формируемого ПЭ.

\section{Выводы}

Результаты моделирования показывают, что на процесс формирования СФЭ влияет положение точки инициирования заряда $\mathrm{BB}$, что дает возможность управлять формой и параметрами кумулятивной струи.

Основная цель данной работы состоит в определении параметров движения и состояния кумулятивных струй. Расчетным путем в результате проведенного численного эксперимента получены кривые, характеризующие зависимость установившихся значений скорости СФЭ от места инициирования заряда ВВ, установлена форма СФЭ боеприпаса.

Для более точного исследования процессов формирования СФЭ требуется уточнение физикоматематических моделей материалов конструкций боеприпасов.

(C) А.Б. Тимошенко, И.Б. Чепков 
В настоящей работе была предпринята попытка экспериментально определить условия функционирования боеприпасов, использующих СФЭ.

Полученные экспериментальные данные не противоречат результатам моделирования и свидетельствуют о достаточно высоком качестве представления процесса функционирования.

Полученные данные могут быть использованы для формирования требований к конструктивному исполнению СФЭ и оценки предполагаемого поражения броневой преграды. Сравнение результатов моделирования с экспериментальными данными позволяет оценить технические решения, применяемые при проектировании боеприпасов повышенной точности, использующих СФЭ.

\section{Список литературы}

1. Walters W.P., Zukas J.A. Fundamentals of shaped charges. New York: John Wiley and Sons, 1989.- 398 p.

2. Чепков И.Б. Направления развития боевых частей на основе снарядоформирующих зарядов/ И.Б. Чепков, А.Б. Тимоменко // Артиллерийское и стрелковое вооружение. 2011. - № 2. - C. 18-22.

3. Chepkov I.B. An experimental investigation of Warheads Functioning with the Self-Forging Fragments// Int.
Scientific - Technical Journal Artillery and Rifle Armaments. 2004. Vol. 1 (10). - P. 21-25.

4. Chanteret P. Y., Broussoux D. Investigation of Shaped Charges with Reverse Initiation at Liner Basis// Proceedings of the 14th International Symposium on Ballistics, Quebec, 1993, - P. 35-44.

5. Steinmann F., Lösch C. Multimode warhead technology studies// 21th International Symposium on Ballistics, Australia, 2004. - P. 164-174.

6. Bondarenko L.I., Lavrikov S.A., Tyrinov A.I. Finite element analysis of hy-pervelocity contact, impact and penetration. Proc. 3rd EUROMECH Solid Mechanics Conference, KTH, Royal Institute of Technology, Stockholm, Sweden, August 18-22, 1997. - P. 56.

7. Lavrikov S.A. A program complex for modeling processes of contact interaction of firm ph. - Proceeding of II-International Conference " Artillery trunk of system, ammunition, means of artillery investigation and management of fire", Scientific \& echnical Centre of Artillery and Rifle Armaments, Kiev, Ukraine, 27 -October 29 1998. - P. 36- 51.

8. Johnson G. R., Cook W.H. A Constitutive Model and Data for Metals Subjected to Large Strains, High Strain Rates and High Temperature// 7th Int. Symposium on Ballistics, The Hague, 1983. - P. 541-547.

9. LLNL Explosive Handbook. Propites of Chemical Explosives and Explosive Simulauts /B.M. Dobratz-Livermor, California, 1981.

Моделювання функціонування бойових частин, що містять снарядоформуючі елементи

А.Б.Тимошенко, І.Б. Чепков

У роботі надані результати чисельного моделювання процесу функціонування кумулятивних струменів, щзо утворюються в результаті підриву зарядів ВР, щзо містять півсферичні (сегментні) облицювання. Отримана інформація про зміну в часі $і$ в просторі параметрів руху $і$ стану уражаючого елемента. У роботі зроблена спроба експериментально визначити умови функиіонування боєприпасів, що використовують снарядоформуючі елементи.

Ключові слова: моделювання, боєприпаси, щзо використовують снарядоформуючі елементи.

\section{Simulation of combat units, containing shell-forming elements}

\section{A.B. Tymoshenko, I.B. Chepkov}

The article presents results of numerical simulation of explosive jets, emerging as a result of explosive content demolition, which contain hemispheric segment liners. Information has been obtained on changes of movement parameters in time and space and engaging element state. An attempt has been undertaken to define experimentally operability of ammo, employing shellforming elements.

Keywords: simulation, ammo, employing shell-forming elements. 